\title{
Intersubjetividad y libertad. Una conversación con Richard Rorty
}

\author{
Maria Herrera y Carlos Pereda
}

Carlos Pereda: Comencemos con una pregunta general ¿cómo se convirtió en filósofo?

Richard Rorty: Fui a la Universidad de Chicago cuando tenía 15 años. En esos dias, el College de la Universidad de Chicago estaba dirigido por filósofos, y casi el currículum por entero era filosofía. Se leía a Platón y Aristóteles en todos los cursos. El director del Collegeera un hombre llamado Richard McKeon, un investigador en Aristóteles, y todo lo que él hacía daba la impresión de que si uno no estudiaba filosofía algo andaba muy mal. La manera en la que fui educado sugería que la filosofía se encontraba en la base de todo, si uno no entendía filosofía sería incapaz de entender cualquier otra cosa.

María Herrera: Nos gustaría que nos dijese algo acerca del cambio en su comprensión de la filosofía en su obra reciente, y también ¿cómo concibe las tareas de la filosofía hoy? En contraste con la manera como la pensaba en los días cuando comenzó su educación.

R.R.: Los aristotélicos y tomistas que me enseñaron eran anti-pragmatistas, y particularmente, anti-Dewey. Todo el mundo en Chicago pensaba que Dewey era algo así como un pensador degradado y que el pragmatismo era un síntoma de la pobreza de la vida intelectual norteamericana. Yo crecí pensando que teníamos que regresar a los griegos para redescubrir las fuentes de la sabiduría filosófica. En algún momento, quizá diez años después de haber comenzado a estudiar filosofia, decidí que Dewey estaba en lo correcto y Aristóteles estaba equivocado. Esto significó para mí el comienzo de un intento para hacer atractivo al pragmatismo norteamericano. Pero mientras tanto, en el tiempo transcurrido entre mis años de licenciatura y el inicio de mi carrera profesional, la filosofía analítica llegó a los Estados Unidos. Entonces, para ser un filósofo había que convertirse en un filósofo 
analítico, así que tuve que reentrenarme a mí mismo. Debí comenzar de nuevo. En lugar de apoyarme en el trasfondo histórico que me habían enseñado, busqué desarrollar un trasfondo analítico. Así, lo que empecé a hacer fue intentar traducir el pragmatismo norteamericano al vocabulario de la filosofia analítica.

M.H.: Entonces, ituvo usted un interés temprano en Dewey?

R.R.: Sólo uno negativo. Cuando estaba en el College, Dewey era quien tenía que ser superado. Pero cuanto más filosofia analítica estudiaba, tanto mejor me parecía Dewey. Me di cuenta de que si uno iba a estar en contra de la tradición metafisica para superar la herencia de Platón y Aristóteles, la manera de hacerlo no era siguiendo el camino lógico-empirista de Carnap y Tarki sino, en lugar de ello, la vía norteamericana de Peirce y Dewey. Así, me encontré diciendo: si uno no va a redescubrir a Aristóteles y Santo Tomás, entonces, debe convertirse en pragmatista en vez de en un filósofo analítico. $O$ al menos, debería tratar de encontrar alguna síntesis entre el pragmatismo y la filosofía analítica, de manera que se filtrara el empirismo de Locke y Hume, de la filosofía analítica.

C.P.: ¿Cómo ve usted desde la perspectiva de su obra actual, las contribuciones a la filosofía analítica que realizó, por ejemplo, al problema mente-cuerpo $u$ a otras cuestiones, tratadas conforme a la ortodoxia analítica? ¿Cómo ve usted ahora las contribuciones que usted hizo en esos años?

R.R.: No pienso que fueran muy importantes. Eran, en gran parte, derivadas de la obra de otra gente, a saber, de Wilfrid Sellars y Hilary Putnam. Todo lo que hice en mis discusiones sobre el problema mente-cuerpo fue recapitular y expander unas pocas cosas que habían dicho Sellars y Putnam. Hoy pienso que la filosofia de la mente ha sido "tomada" por Daniel Dennet. Él es el más importante filósofo de la mente desde Ryle. Lo que yo estaba haciendo era justamente una versión norteamericana del anticartesianismo de Ryle, una versión que ahora ofrece Dennet en mucho mejor forma.

M.H.: En conexión con su obra más reciente ¿cómo describiría usted las contribuciones más importantes de Dewey para una nueva comprensión de la filosofía en nuestros días?

R.R.: Pienso que lo que Dewey hizo fue decir: no busquen fundamentos metafísicos o empistemológicos o filosóficos para una sociedad democrática. En lugar de ello inviertan la pregunta, interroguen: puesto que lo que queremos es una sociedad democrática ¿qué obstáculos ha puesto la filosofia en el camino para alcanzar tal 
sociedad? Pienso que la respuesta de Dewey fue que todo lo que la filosofia tiene que hacer por una sociedad democrática es aclarar el camino, eliminar viejas preconcepciones filosóficas, imágenes y vocabularios que no son adecuados para tal sociedad. En particular, pienso que el punto central de Dewey fue que lo que llamamos "conocimiento" es simplemente el producto de la búsqueda de acciones exitosas. La verdad no es un fin en sí mismo. No hay tal cosa como la persecución del conocimiento como fin en sí mismo. La verdad depende de una interacción exitosa con el contexto. Esta concepción darwiniana de la investigación humana permitió a Dewey decir que la pregunta acerca del conocimiento no es una pregunta acerca de la naturaleza de la mente cognoscente, o acerca de la naturaleza del sujeto. Es una pregunta acerca de la naturaleza de la comunidad a cuyos propósitos atiende la investigación. El efecto de la teoría pragmatista de la verdad, como Dewey la desarrolló, fue desplazar a la filosofia lejos de la metafísica y la epistemología y conceder a la política prioridad sobre cualquier otra área de la cultura. Así, lo que me impresionó acerca de Dewey fue la profundidad de su crítica a los griegos, en particular, su repudio de la noción de contemplación como el bien más alto de la mente y su consecuente politización de la filosofia.

C.P.: Pero en este sentido, es un poco sorprendente que usted haya vinculado a Dewey con Heidegger, pues este último tenía una opinión muy alta de los griegos.

R.R.: Lo que yo admiro en Heidegger es su visión de cierta dialéctica interna dentro de la metafísica occidental que conduce al pragmatismo que compartían Nietzsche y William James. La discusión en Heidegger sobre cómo llegamos de Platón a Nietzsche (o como nosotros los norteamericanos diriamos, de Platón a Emerson y James) es una manera brillante de contar la historia de la filosofía occidental. Pero Heidegger pensaba que el pragmatismo era un desastre y yo pienso que es grandioso. Heidegger creyó que habíamos perdido la grandeza de los griegos, mientras que yo estoy de acuerdo con Dewey en que los griegos fueron una especie de escalera que nos permitió llegar al siglo xIx, pero ahora debemos desecharla, ya que hemos superado el siglo xix.

C.P.: Usted dice que en Dewey nosotros vamos de la metafísica y epistemologia a la política. Pero leyendo a Dewey, tengo otra impresión. Diría que vamos de la metafísica y la epistemología a la pedagogía. Por otra parte, quiero hacerle notar que Dewey fue extremadamente importante en la pedagogía de muchos países en 
América Latina. Desde los años veintes a los años cuarentas, se leyó a Dewey con especial interés por su contribución a la educación.

R.R.: Este fue su efecto en todas partes. Las obras pedagógicas son lo que la gente recuerda. Probablemente a Dewey le hubiera gustado ver su obra como yendo de la metafísica y la epistemología a la pedagogía, en lugar de a la política. Pero pienso que en algún sentido viene a ser lo mismo. Pues si usted se pregunta: ¿por qué deberíamos adoptar la pedagogía de Dewey?, la respuesta es política. Es porque se quiere una sociedad igualitaria, una en la cual no se den más contrastes entre los conocedores y los hacedores, entre los contempladores y los trabajadores o entre los sacerdotes y los obreros. La pedagogía de Dewey quiso destruir la idea del conocimiento como una ocupación humana diferente al trabajo, la industria o el arte.

M.H.:Dos preguntas quiero hacerle en relación con lo que acaba de decir. Pienso que estas dos cuestiones no siempre se han comprendido bien en su obra. Una, es la relación entre filosofía y política, la otra, la clase de discurso que es la filosofía ahora. $\mathrm{Si}$ usted quiere renunciar a las pretensiones especiales de la filosofía como un meta-discurso o como el acceso a un modo privilegiado de conocer, y quiere acudir a otros discursos tales como la literatura, no obstante ¿no concibe alguna clase de especificidad para las tareas de la filosofía? ¿O piensa que ésta se fusionará con otras formas de discurso?

R.R.: Considero al filósofo como un hombre o mujer de letras que tiene una especial familiaridad con ciertos textos: Platón, Aristóteles, Santo Tomás, Descartes, Kant, Hegel, etcétera. Se necesitan especialistas en esos textos porque no se puede leer a uno sin haber leído a los otros. Se tiene que conocer la tradición entera para entender de qué se trata. Si no se ha leído a los griegos no se puede percibir el sentido del idealismo alemán. Si no se ha leído a Hegel no se puede comprender el sentido de una gran cantidad de textos de Marx. Si no se hubiera leído a Nietzsche no se entendería a Heidegger, etcétera. Alguien tiene que conocer la secuencia entera. La única especificidad que tienen los filósofos es que son responsables de esos textos. Conocen esa tradición de manera similar a como los historiadores del arte conocen las relaciones entre el griego arcaico y la escultura egipcia o Miguel Ángel y Rodin.

M.H.: Además de tener una relación con un cuerpo específico de textos ¿cree usted que los filósofos tienen también un conjunto más menos específico de problemas, aunque ellos puedan variar en la historia? Yo no digo que los filósofos siempre hablen de lo mismo. 
Lo que tengo en mente es quizás una tensión entre argumentación y descripción o narrativa. ¿Cree que hay un cambio importante en la problemática o en las maneras de tratar estos problemas ahora?

R.R.: Ha habido un cambio dirigido hacia la narrativa entre los intelectuales que uno llama "filósofos" desde Hegel. Hegel nos ayudó a narrativizar la filosofía. Pero se han dado reacciones en contra de esta narrativización. Husserl fue una de esas reacciones y Frege y Russell otra. Pero sospecho que a la larga, Hegel ganará. Los intentos de revivir una técnica pre-hegeliana de argumentación filosófica entre los fenomenólogos o entre los lógicos (gente como Russell y Frege, "lógica", pues, en el sentido amplio de "lógica") probablemente conducirá al fracaso. Por lo tanto, considero que los únicos problemas que permanecerán serán problemas muy abarcadores y difusos como: religión versus ciencia, ciencia versus política, cosas de esa magnitud. La gente siempre tendrá esos problemas pues siempre buscará algún substituto para Dios. Por eso, se tendrá que decir algo de los intentos de construir "substitutos" de Dios. Siempre habrá alguien que sugiera que la política puede hacerse científica entregándosela a los expertos o a los sabios..., así que siempre habrá algo reminiscente de lo que hablaban Hegel y Platón.

C.P.: Lo que dice es un poco sorprendente para mí viniendo de alguien que al mismo tiempo tiene tan alta opinión de colegas como Dennet, Davidson o Putnam, quienes hacen más o menos filosofía tradicional, no filosofia narrativa, sino una filosofía que puede ser llamada sistemática en un sentido muy amplio.

R.R.: Probablemente los veo de un modo diferente de como ellos se ven a si mismos. A Davidson no le gusta la manera en que hablo de él. Lo admiro mucho, pero cuando lo elogio él piensa que es por razones equivocadas. Veo a Davidson y a Dennet como gente que nos ha ayudado a librarnos de ciertas nociones humeanas y kantianas que aún sobrevivian en James y en Dewey, nociones como "experiencia", por ejemplo. Dewey y James se refieren constantemente a la verdadera naturaleza de la experiencia. Pienso que el logro de gente como Putnam y Dennet, Sellars y Davidson, es habernos liberado de nociones como mente, conciencia o experiencia, todos los supuestos intermediarios entre el comportamiento lingüístico - las marcas y ruidos que hacemos e intercambiamos con los otros- y el mundo en que vivimos. Dennet y Davidson han eliminado la noción de subjetividad, y esto es un logro importante. Pero a ellos no les gustaría esta caracterización. Piensan que están haciendo algo más preciso que eso. 
C.P.: ¿En este sentido, usted vería el proyecto entero de Thomas Nagel como completamente equivocado?

R.R.: Sí, y como extremadamente reaccionario. Dennet una vez me dijo que si Tom Nagel no existiera, él y yo tendríamos que inventarlo. Es nuestro perfecto oponente. Está a favor de todo lo que la filosofía analítica ha tratado de librarse. Cree en estados mentales incomunicables y en una subjetividad más allá del alcance del lenguaje. Si Tom Nagel tuviera razón, estariamos de vuelta en el siglo xvir.

M.H.:Regresemos a la pregunta sobre las relaciones entre filosofia y política. Estoy de acuerdo con usted en que la filosofía no tiene mucho qué ofrecer como solución a los problemas de nuestro mundo. Pero hay algo que no es enteramente claro acerca de lo que usted piensa de esta relación. Por ejemplo, en el caso de los dramáticos cambios recientes en el mundo, tales como la caída del socialismo, parecería que tenemos que enfrentarnos con lo que usted ha dicho acerca de la "mera contingencia" de la historia, el hecho de que los eventos del mundo no son predecibles; pero al mismo tiempo, esto lo hace a uno pensar que las ganancias de la democracia podrían no ser permanentes. El hecho de que la historia sea sólo contingencia podría requerir de nosotros alguna forma de re-descripción de la historia de los regímenes democráticos. Después de todo, la historia de Occidente no es sólo la historia de la democracia, sino también la historia del poder, y recientemente, de la re-colonización del Tercer Mundo. Si nos concierne el futuro de la democracia podría ser interesante intentar alguna clase de re-descripción creativa y crítica de su historia actual, una que incluya la historia de las relaciones entre el Primer y el Tercer mundos. Pero por ello no entiendo ninguna forma de totalizar a una posición política dogmática, sino al contrario, pienso que justamente no tenemos ahora nuevas formas de entender lo que está sucediendo en el mundo. Por ejemplo, podemos ver como pérdidas recientes de la democracia a la censura militar de la prensa en la Guerra del Golfo Pérsico. ¿Qué diría usted acerca de todo esto?

R.R.: Es verdad que la izquierda política en las democracias va a tener que encontrar formas enteramente nuevas de hablar. Por mucho tiempo, la izquierda contrastó el presente escenario capitalista con una gloriosa estructura social post-revolucionaria. Pero es difícil para nosotros especular acerca de lo que sucedería después de que fuera abolida la propiedad privada ahora que nadie quiere abolir la propiedad privada. Me parece que todo lo que le queda a la izquierda democrática es lo que los marxistas llamaban el 
"reformismo pequeñoburgués meramente social democrático" Así, el modelo para los países democráticos se convierte en el de los Estados europeos continentales como Holanda o Suecia, ejemplos exitosos de Estados de bienestar. Lo curioso es que los paises anglo-sajones están más atrasados que el continente europeo en el desarrollo del Estado de bienestar. Están también detrás de ellos, en el caso de los Estados Unidos por lo menos, al encontrarse bajo la dominación de lo que el presidente Eisenhower llamaba "el complejo militar-industrial". Comparado con Holanda, Francia, Alemania o Italia, los Estados Unidos son un cuartel, un Estado de seguridad nacional. Me parece que los Estados Unidos, que siempre habían estado a la vanguardia de la democracia, han ahora resbalado hacia atrás. No son sólo más el modelo a seguir sino el lugar en donde la democracia es más frágil. Es mucho más fácil imaginar que Estados Unidos se volviera fascista a que cualquier otro pais europeo se volviera fascista. Hay escenarios perfectamente razonables en los que a una depresión en los Estados Unidos podría seguir un gobierno militar fascista y el fin de la democracia constitucional. Por supuesto, tales escenarios son posibles en cualquier país. Pero los Estados Unidos, simplemente por razones históricas accidentales, son justamente más frágiles que la mayoría de las democracias constitucionales del Atlántico del Norte; ¿esto responde a su pregunta?

M.H.:Sí, pero ¿piensa usted que los intelectuales, no solamente los filósofos, tienen un rol que cumplir para expander la conciencia de esto, o para tratar de influir en la opinión pública?

R.R.: Los intelectuales poseen tal rol, si bien no más los filósofos que los otros intelectuales. Me parece que ésta es una tarea para la gente que lee libros. Pero la gente que lee libros de filosofía no tiene nada distintivo qué decir al respecto.

M.H.: Entonces sería correcto afirmar que usted ve la tarea política de un filósofo como la de cualquier otro intelectual, nada específico, pues, acerca de la filosofía.

R.R.: Sí. En tanto que existe un desacuerdo residual entre Habermas y yo, se debe a que Habermas todavía concibe a la filosofía a la manera alemana, como algo en el centro del mundo intelectual.

C.P.: Pero los pragmatistas norteamericanos fueron filósofos muy influyentes, incluso en América Latina, como mencionamos antes, a través del impacto de Dewey en la educación.

R.R.: Esto es verdad. Emerson y James y Dewey fueron tan influyentes como lo ha sido cualquier otro intelectual norteamericano. Pero esto 
no se debió a que hubieran sido filósofos sino a que eran mentes originales. Dewey jugó un rol análogo al de Ortega. Era simplemente el intelectual más interesante, con las ideas más abarcadoras e interesantes. Ambos fueron accidentalmente profesores de filosofia, pero podrían igualmente haber sido profesores de política o profesores de historia. No hubiera habido mucha diferencia. Nadie sabe si hay que llamar o no a Emerson un filósofo pero ¿a quién le importa? Hay una cierta tradición que va de Emerson a Dewey. A menudo se piensa en Walt Whitman y James como dos emersonianos, uno de los cuales escribió filosofía y psicología, y el otro poesía, pero básicamente estaban haciendo la misma cosa.

C.P.: Sin embargo, la situación hoy es diferente: los filósofos analíticos han hecho de la filosofía una profesión, extremadamente especializada y diferenciada.

R.R.: Pero es por eso también que nadie fuera de la profesión sabe nada acerca de ella. Ninguno de los otros intelectuales norteamericanos ha oído alguna vez de la filosofía analítica. Nombres como Davidson y Quine no significan nada al intelectual medio norteamericano, mientras que nombres como Derrida y Foucault significan mucho. Estos dos filósofos no se enseñan en los departamentos de filosofía. No obstante, como intelectuales en un sentido más amplio juegan un papel muy significativo en las universidades norteamericanas.

M.H.: ¿Y Habermas?

R.R.: La razón por la que Habermas es importante es porque reaccionó en contra de la figura dominante de la generación previa, Heidegger, y ofreció una re-interpretación del rol cultural de gente como Marx, Nietzsche, Hegel, etcétera, lo cual era buscado en la nueva Alemania de la post-guerra. Alguien tenía que decir algo acerca de Heidegger y Nietzsche, y Habermas fue el hombre adecuado en el tiempo adecuado. No había ningún rol equivalente que desempeñar en Inglaterra $o$ en los Estados Unidos, porque no había ningún Heidegger a quien superar. No había ninguna tradición intelectual que necesitase ser criticada desde un punto de vista político a la manera en que Habermas criticó a Heidegger. Así, no había ninguna necesidad de un Habermas norteamericano o británico. Pero esto no quiere decir que muchos filósofos analíticos no hayan hecho cosas muy interesantes. Incluso aunque ningún intelectual fuera de los departamentos de filosofía haya oído hablar de Davidson, pienso que en los próximos dos siglos, Davidson será mirado en retrospectiva como alguien que hizo algo muy útil, tal como ahora miramos a 
Frege y valoramos la utilidad de su contribución, aunque nadie hubiera oído hablar de Frege cuando Frege estaba vivo.

M.H.: Algo que me intriga en su obra es una cierta falta de simpatía por las ciencias sociales. Considero que si las ciencias sociales no son entendidas de una manera positivista, nos pueden ofrecer algunas sugerencias interesantes para pensar las prácticas sociales, la clase de "descripciones densas" de las prácticas sociales que usted ha elogiado algunas veces. Podríamos pensar en los informes etnográficos orientados hermenéuticamente o en estudios en la pragmática del lenguaje o incluso en el psicoanálisis como usted lo trata en su ensayo sobre Freud, que podrían ser creativamente apropiados por filósofos de manera tal que sugirieran nuevas formas de mirar a ciertos problemas... ¿Qué clase de relaciones ve usted entre las ciencias sociales y la filosofia?

R.R.: No creo en las ciencias sociales como ciencias o como programas de investigación. Pienso que son lugares en donde uno ocasionalmente encuentra un escritor interesante, un Malinowski o un Geertz o un Schumpeter o un Weber. De tanto en tanto hay un antropólogo interesante o un sociólogo o un economista y entonces todo el mundo lo lee. Aquí, de nuevo, estoy en desacuerdo con Habermas, quien piensa en Chomsky y Piaget como representando a una clase distintiva de investigación, una investigación "reconstructiva". No encuentro mucho interés ni en los programas de Chomsky ni en los de Piaget. Habermas parece tener una suerte de fe en una analogía entre la física y la sociología o psicología. Pero yo no veo ninguna analogía. No creo que éstas sean disciplinas que convergen hacia una solución. Son sólo oportunidades de emplear más gente en las universidades. Tanto más gente se emplee en las universidades, tanto mejores serán las oportunidades de que surja alguien brillante y escriba un libro que todo el mundo quiera leer. Pero esto no es porợte él o ella sean científicos sociales, sino porque son intelectuales que se topan con una nueva idea mientras estudian una tribu o a los niños.

M.H.: ¿Usted no cree, entonces, en nada más que una noción transitoria de objetividad, "objetividad" como una "noción de trabajo" en estas disciplinas, algo que hay que asumir pero sin las pretensiones fuertes que querría avanzar Habermas, por ejemplo, en su apropiación de Kohlberg y Piaget?

R.R.: No veo nada importante en la apropiación de Kohlberg y Piaget. Me parece que objetividad es sólo intersubjetividad. En otras palabras, es ser capaz de ponerse de acuerdo con un grupo por la vía de la 
persuasión en lugar de por la fuerza. Habermas retiene una suerte de progreso hacia la objetividad, mientras que considero que lo bueno acerca de reemplazar a una razón centrada en el sujeto por una razón comunicativa es alejarse de la idea del conocimiento como relación entre un sujeto y un objeto. Lo que nosotros buscamos no es lograr una mayor objetividad, sino conseguir mayor libertad intelectual, mayor consenso político. Se puede hablar, si quieren, de objetividad, pero el término está, de algún modo, pasado de moda.

M.H.: Pero no tenemos con qué reemplazarlo...

R.R.: Quizá, libertad. 